\title{
POST-MORTEM DESCRIPTION OF SLIPPED CAPITAL FEMORAL EPIPHYSIS
}

\author{
D. R. COOPERMAN, L. M. CHARLES, M. PATHRIA, B. LATIMER, G. H. THOMPSON
}

\author{
From Case Western Reserve University and Cleveland \\ Museum of Natural History, Ohio
}

\begin{abstract}
We found, in a museum collection of skeletons, nine adult hips with untreated slipped capital femoral epiphyses. All the specimens were from men, five black and two white. Their mean age at death was 44 years. Seven of the femora were retroverted beyond neutral and five had true varus deformities.

Osteoarthritis was detected in eight of the hips and the most severe degeneration was seen in the most deformed hips. Radiography revealed that cysts which appeared to occupy the femoral head in fact lay in the metaphyseal bone of the femoral neck.
\end{abstract}

Chronic slipped capital femoral epiphysis (SCFE) is a disorder characterised by gradual displacement of the femoral neck from the capital femoral epiphysis which remains in the acetabulum; this results in retroversion and altered mechanics of the hip. The incidence of this disorder in the general population is approximately 2 per 100000 (Kelsey, Keggi and Southwick 1970; Busch and Morrissy 1987). Although rare, it is, nevertheless, one of the most common hip disorders of adolescence. Furthermore, several investigators have suggested that there is an asymptomatic form of SCFE which may predispose to premature degenerative osteoarthritis in adulthood (Murray 1965; Stulberg et al 1975). This concept is not accepted by all (Resnick 1976).

Since the original description of SCFE by Pare in 1572, there have been many contributions to our knowledge of its pathology, aetiology, natural history, epidemiology, and treatment. Unfortunately, there is little information about the morphology of the hip from post-mortem specimens in untreated SCFE. We therefore

D. R. Cooperman, MD, Assistant Professor of Orthopaedic Surgery L. M. Charles, MD, Intern, University of Michigan

M. Pathria, MD, Assistant Professor of Radiology

G. H. Thompson, MD, Associate Professor of Orthopaedic Surgery and Paediatrics, Director of Paediatric Orthopaedics

Case Western Reserve University, 2074 Abington Road, Cleveland, Ohio 44106, USA

B. Latimer, PhD, Director of Physical Anthropology Laboratory Cleveland Museum of Natural History, Cleveland, Ohio 44106, USA.

Correspondence should be sent to $\mathrm{Dr} \mathrm{D}$. R. Cooperman at Rainbow Babies and Children's Hospital, 2074 Abington Road, Cleveland, Ohio 44106, USA

(C) 1992 British Editorial Society of Bone and Joint Surgery

$0301-620 X / 92 / 4415 \$ 2.00$

J Bone Joint Surg [Br] 1992; 74-B :595-9. reviewed the specimens in the Hamann-Todd osteological collection to determine the morphological consequences of untreated SCFE.

\section{MATERIALS AND METHODS}

The Hamann-Todd collection of the Cleveland Museum of Natural History consists of 2972 complete human skeletons collected between 1893 and 1938. There are 2457 males (837 black) and 515 females (287 black). Their ages at death ranged from one to 96 years and all but 44 were over 12 years old at the time of death. Medical histories, including the cause of death, are available for most of the specimens. All had postmortems at the Cleveland city morgue.

There were 20 skeletons with grossly abnormal femoral heads and necks. Further scrutiny, including radiographic evaluation, indicated that seven definitely showed the sequelae of SCFE and that none of these had been treated surgically. The remaining abnormal specimens had signs of Legg-Calvé-Perthes disease, fracture of the femoral neck, osteonecrosis, or inflammatory disorders. Two of the seven skeletons with SCFE had bilateral involvement, giving a total of nine hips available for study.

Details of the seven skeletons (nine hips) are given in Table I. All were male and five were black. The mean age at death was 44 years (26 to 68).

Morphological characteristics. The deformity of the proximal femur was graded according to the degree of retroversion of the femoral head as absent, mild, moderate or severe. The femurs were placed on a level surface resting on three points, the posterior aspects of the medial and lateral femoral condyles distally and a 


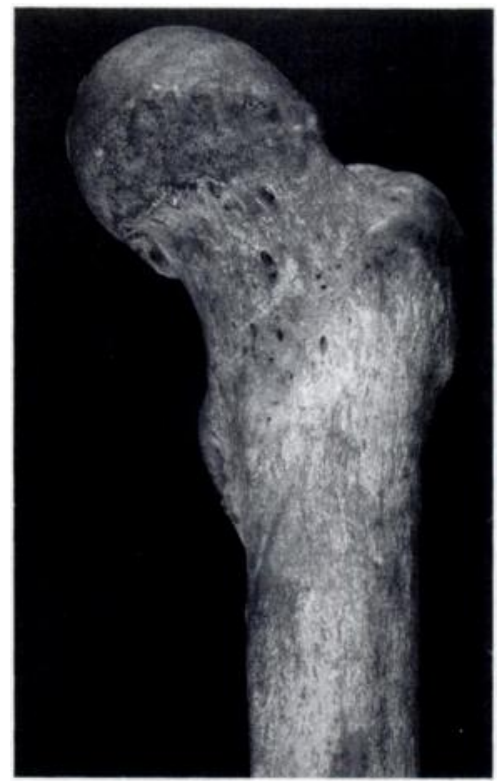

Fig. 1a

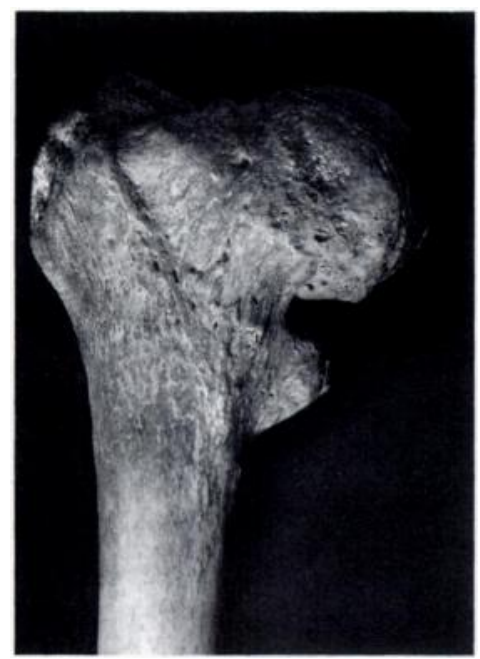

Fig. 2a

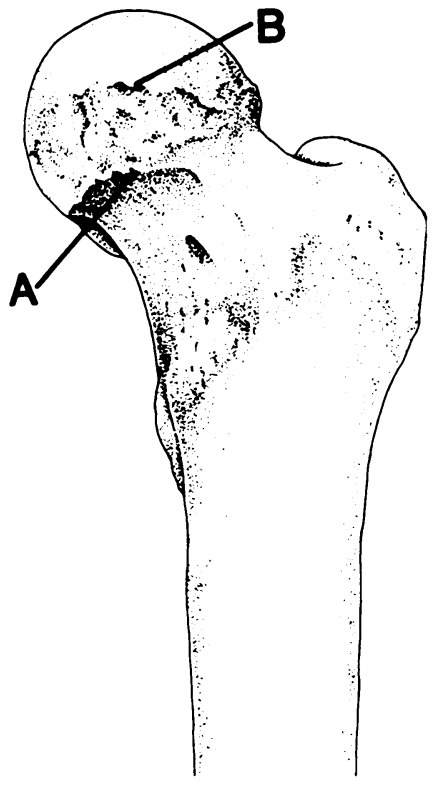

Fig. Ib

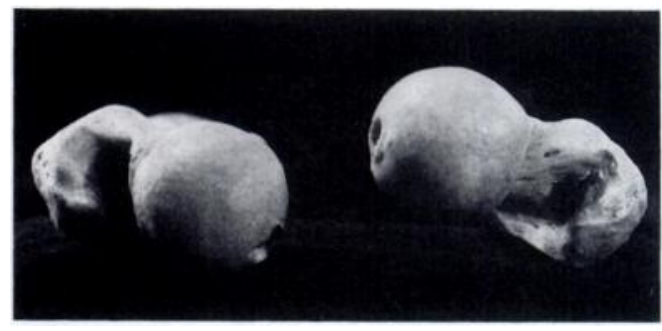

Fig. 1c

Figure la - Anterior aspect of the left femur in specimen 4. Figure $1 \mathrm{~b}$ - Diagram showing the separation between the original epiphyseal margin (B) and the femoral neck (A). Figure lc-Considerable retroversion of the left femur compared with the right.

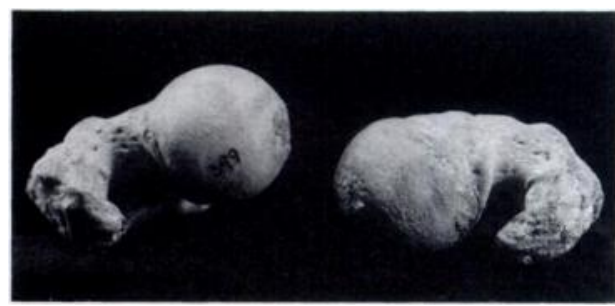

Fig. 2c

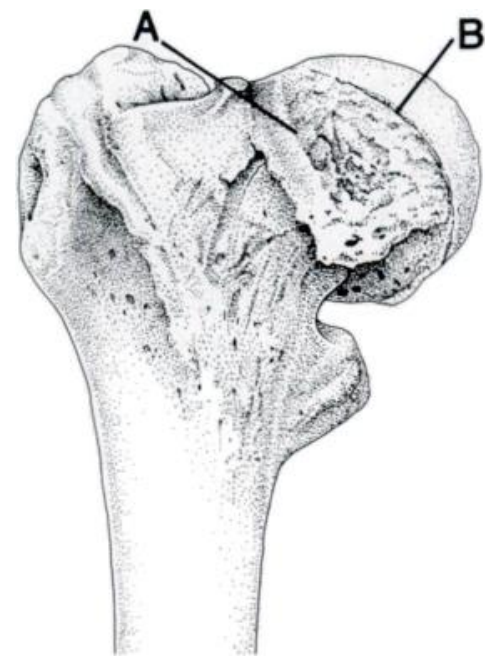

Fig. 2b proximal point. If there was minimal retroversion this proximal point was the greater trochanter; in moderate or severe retroversion it was the femoral head. The version of the femoral head was then measured with a goniometer as the angle between the flat surface on which the bone lay and a line from the piriform fossa to the centre of the femoral head. This measurement gave the true angle of retroversion more accurately than did radiography. The femoral neck was deformed in most affected hips and could not be used for these measurements. Retroversion, when present, was assigned a minus value and anteversion a positive value. Hips with anteversion or as little as $-10^{\circ}$ of retroversion were considered to be mild slips; those with between $-10^{\circ}$ and $-29^{\circ}$ of retroversion as moderate; and those with $-30^{\circ}$ or more as severe. Normal anteversion was defined as $8.5^{\circ}$ for the left and $11^{\circ}$ for the right hip (SD $\pm 8^{\circ}$ ), based on a previous analysis of 108 randomly selected male hips in the same skeletal collection (Latimer, personal communication, 1991).

The angle of varus of the proximal femur was measured as the articulotrochanteric distance (ATD) with the femur held upright, resting on its medial and lateral femoral condyles. The ATD is the vertical distance between horizontal lines drawn tangentially to the top of the femoral head and to the tip of the greater trochanter. Radiographic characteristics. Anteroposterior and lateral radiographs were taken of the proximal femur and the radiographic and gross appearances of osteoarthritis were classified as described by Boyer, Mickelson and 
Table I. Features of seven male skeletons (nine hips) with slipped capital femoral epiphyses (SCFE)

\begin{tabular}{|c|c|c|c|c|c|c|c|c|c|c|}
\hline \multirow[b]{2}{*}{ Specimen } & \multirow[b]{2}{*}{$\begin{array}{l}\text { Age (yr) } \\
\text { at death }\end{array}$} & \multirow[b]{2}{*}{$\begin{array}{l}\text { Cause } \\
\text { of death }\end{array}$} & \multirow[b]{2}{*}{ Race } & \multirow[b]{2}{*}{$\begin{array}{l}\text { Affected } \\
\text { hip }\end{array}$} & \multicolumn{2}{|c|}{$\begin{array}{l}\text { Version of } \\
\text { femoral head* } \\
\text { (degrees) }\end{array}$} & \multirow[b]{2}{*}{$\begin{array}{l}\text { Severity } \\
\text { of slip }\end{array}$} & \multicolumn{2}{|c|}{$\begin{array}{l}\text { Articulotrochanteric } \\
\text { distance (mm) }\end{array}$} & \multirow[b]{2}{*}{$\begin{array}{l}\text { Grade of } \\
\text { osteoarthritis }\end{array}$} \\
\hline & & & & & Left & $\frac{\text { Right }}{\text { Righ }}$ & & $\begin{array}{l}\text { Affected } \\
\text { hip }\end{array}$ & $\begin{array}{l}\text { Normal } \\
\text { hip }\end{array}$ & \\
\hline 1 & 68 & Mitral insufficiency & White & Left & -10 & +12 & Moderate & 25 & 25 & 3 \\
\hline 2 & 63 & Myocarditis & White & Right & +10 & -2 & Mild & 9 & 27 & 2 \\
\hline 3 & 42 & $\begin{array}{l}\text { Hypertensive heart } \\
\text { disease }\end{array}$ & Black & Left & -10 & +13 & Moderate & 9 & 15 & 2 \\
\hline 4 & 40 & Unknown & Black & Left & -18 & +10 & Moderate & 27 & 27 & 2 \\
\hline 5 & 36 & Tuberculosis & Black & Left & -31 & +9 & Severe & 0 & 18 & 3 \\
\hline 6 & 31 & Tuberculosis & Black & $\begin{array}{l}\text { Right } \\
\text { Left }\end{array}$ & +17 & -13 & $\begin{array}{l}\text { Mild } \\
\text { Moderate }\end{array}$ & $\begin{array}{l}24 \\
12\end{array}$ & & $\begin{array}{l}0 \\
2\end{array}$ \\
\hline 7 & 26 & Tuberculosis & Black & $\begin{array}{l}\text { Right } \\
\text { Left }\end{array}$ & +8 & -15 & $\begin{array}{l}\text { Moderate } \\
\text { Mild }\end{array}$ & $\begin{array}{r}9 \\
18\end{array}$ & & $\begin{array}{l}3 \\
2\end{array}$ \\
\hline
\end{tabular}

*see text

Ponseti (1981): grade 0, no degenerative changes; grade 1 , no more than one subchondral cyst or osteophyte, no bone sclerosis; grade 2, one or a few subchondral cysts as well as osteophytes, minimal subchondral sclerosis; and grade 3, multiple subchondral cysts and osteophytes, marked subchondral sclerosis. Narrowing of the joint space could not be evaluated as the articular cartilage had been destroyed during the initial preparation of the skeletons.

\section{RESULTS}

The incidence of SCFE in the Hamann-Todd collection was $1 / 160$ for black males and $1 / 800$ for white males. The left hip was affected in three skeletons, the right in two, and two were bilateral. There were three mild slips, five moderate, and one severe. We believe that our criteria closely match the standard radiographic criteria for mild, moderate and severe SCFE (Weinstein 1984). Morphologically, there was a roughened surface of exposed metaphyseal bone anteriorly between the site of the original capital epiphysis and its displaced position (Fig. 1). The amount of exposed metaphyseal bone varied with the degree of slip (Fig. 2). We could not tell if at one time this area had been covered with fibrocartilage.

Retroversion was seen in seven of the nine hips with SCFE. The five normal hips in the unilateral cases had a mean of $11^{\circ}$ of anteversion (9 to 13) which is within one standard deviation of the mean for the Hamann-Todd collection. In unilateral cases with SCFE the mean retroversion was $-14^{\circ}(-2$ to -31$)$. The bilateral cases each had one mild and one moderate SCFE. The two with mild slip were not retroverted while the two with moderate slip were retroverted $-13^{\circ}$ and $-15^{\circ}$.

In the five unilateral cases the hips on the normal side had a mean ATD of $22 \mathrm{~mm}$ (15 to 27). Three of the unilateral SCFE hips had decreased ATD, measuring 9, 9 , and $0 \mathrm{~mm}$, respectively 17,6 and $18 \mathrm{~mm}$ less than the opposite normal side. Two of the bilateral cases had decreased ATD of $12 \mathrm{~mm}$ and $9 \mathrm{~mm}$.

Osteoarthritis. On gross inspection, there was evidence of osteoarthritis in eight of the nine specimens. The one hip with severe retroversion and the two with moderate retroversion all had large femoral head osteophytes and acetabular erosions (Fig. 3). These patients had been 68 , 36 and 26 years old at death. The skeleton of the 68 -yearold subject also had eburnation of the femoral head, the only specimen to show this. Two mild and three moderately deformed hips had slight osteoarthritis with small acetabular erosions (less than $2.0 \mathrm{~mm}$ ) and/or small femoral osteophytes. The ages at death ranged from 31 to 63 years. One hip with mild involvement showed no gross evidence of degenerative joint disease.

Seven of the nine acetabula had anterior erosions and five of these also had posterior and superior erosions. The femoral osteophytes were mainly anterior.

The knees of all nine specimens appeared to be normal, with no evidence of osteoarthritis and the unaffected hips in the five unilateral specimens were also free from degenerative changes.

Radiography revealed no evidence of osteoarthritis in the one mild SCFE hip. Five hips had grade 2 osteoarthritis. The severely retroverted hip and two moderately retroverted hips had grade 3 osteoarthritis (Fig. 4).

Radiographic cysts were difficult to correlate with the gross findings. Specimen 7 (right hip) had multiple acetabular erosions ( 2 to $5 \mathrm{~mm}$ ) and considerable radiographic evidence of osteoarthritis in the acetabulum (Fig. 4). Specimen 5 had similar acetabular erosions but only a few small radiographic cysts in the acetabulum (Fig. 3). Cysts that appeared to be in the femoral head on the anteroposterior radiograph were found in four of the nine femora, but, surprisingly, they were not seen in the epiphysis on the lateral radiograph. These cysts actually lay in the roughened anterior metaphyseal bone that was 


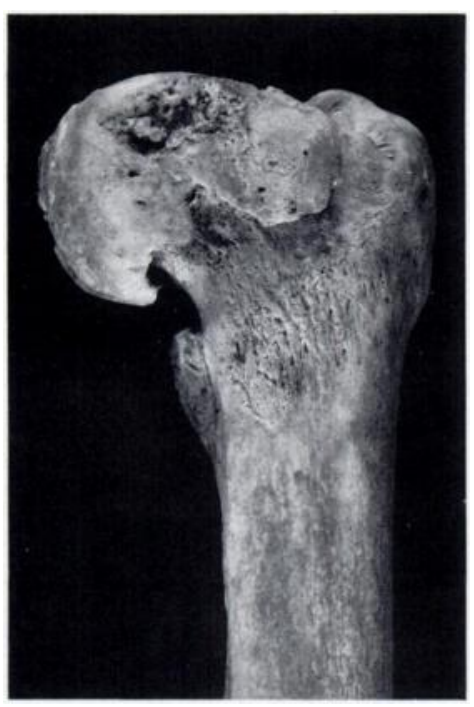

Fig. 3a

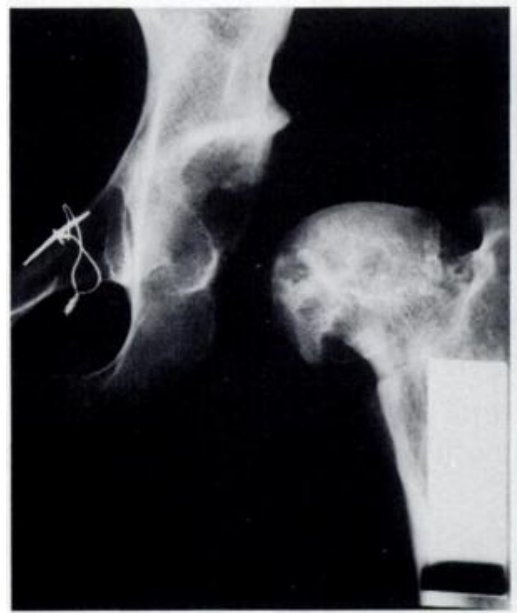

Fig. 3d

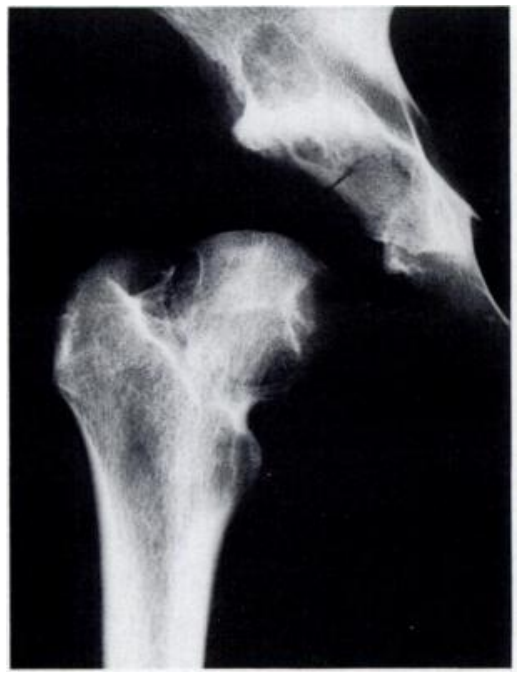

Fig. 4a
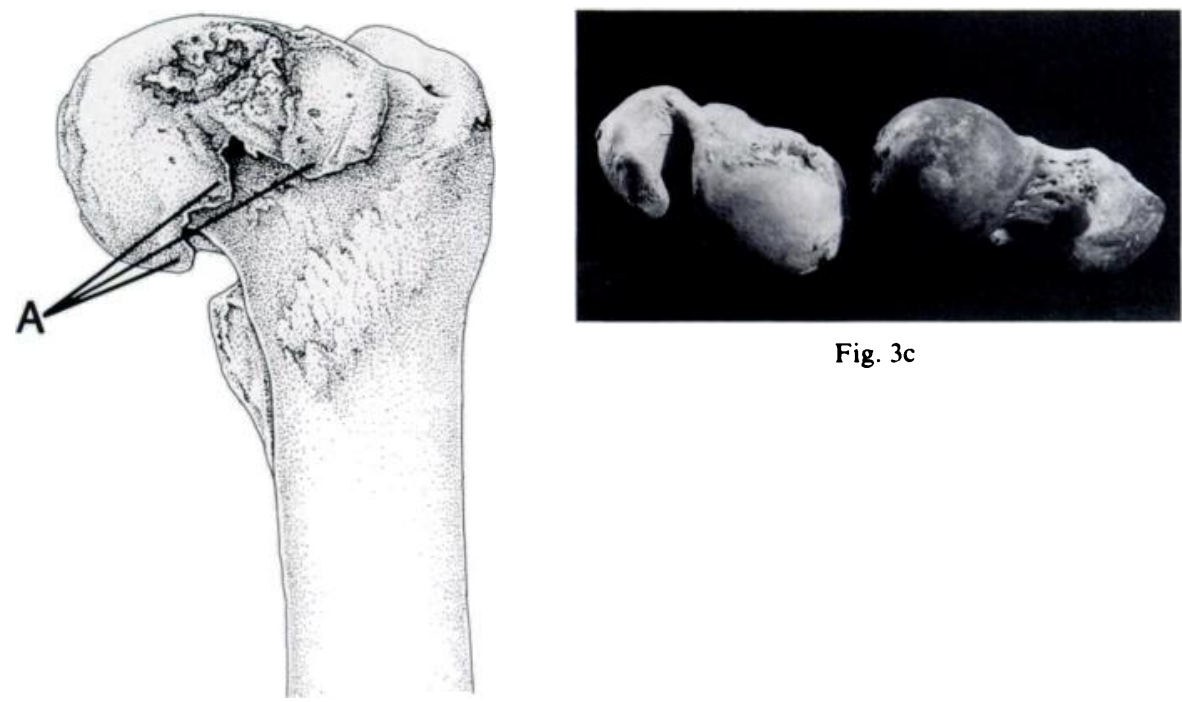

Fig. 3c

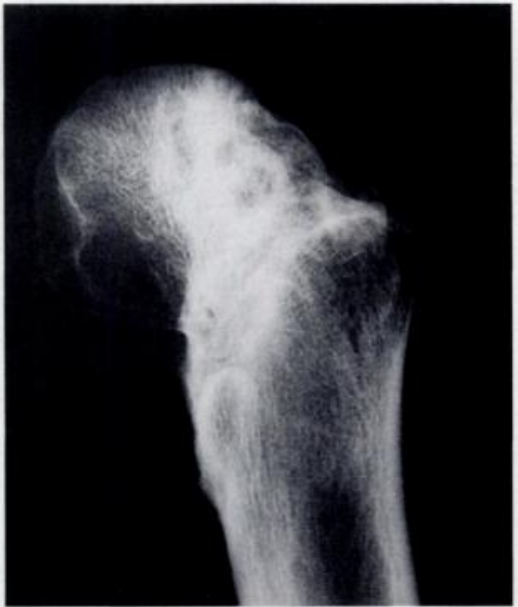

Fig. 3e

Figure 3a - Anterior aspect of the left femur in specimen 5 . Figure $3 \mathrm{~b}$ - Diagram showing the large femoral osteophytes (A). Figure 3c-Severe retroversion of the left hip compared with the right. Figure 3d - Anteroposterior radiograph of the left hip to show cysts apparently in the femoral head. Figure $3 e-$ Lateral radiograph showing that the cysts are, in fact, in the exposed metaphysea bone, anterior to the retroverted femoral head. 
exposed between the original femoral neck junction and the final position of the epiphysis (see Figs $3 \mathrm{~d}$ and $3 \mathrm{e}$ ).

\section{DISCUSSION}

SCFE is a condition which affects a certain subset of the population. It is more common in large adolescent males (male/female ratio $=2.5 / 1 ;$ Kelsey et al 1970). In males the left hip is more commonly affected than the right but not so in females (Hägglund, Hansson and Ordeberg 1984; Hansson, Hägglund and Ordeberg 1987). Black children are more susceptible than white children (Weinstein 1984).

The incidence of SCFE in the general population is currently thought to be about 2 per 100000 (Kelsey et al 1970; Busch and Morrissy 1987) but this is probably an underestimate because the disorder may be silent, and many patients are never identified. In the collection, the incidence was $1 / 160$ for black males and $1 / 800$ for white males. It is difficult to estimate the possible effects of nutrition and disease in this group who lived during the late 19th and early 20 th centuries.

Retroversion was a common finding in the hips with SCFE and was not observed in the contralateral normal hips in the five unilateral specimens. In those with retroversion, the neck was arched in the coronal plane, so that a straight line could not be drawn through it, a shape which must have resulted from years of remodelling.

Degenerative joint disease was seen in eight of the nine hips and was most severe in those with a low ATD and considerable retroversion, although there were some surprisingly good outcomes in cases with considerable retroversion and a normal ATD (specimens 2 and 4).

The radiographic cysts in the femur were all located in the anterior metaphyseal bone exposed as the epiphysis slips posteriorly and all the acetabular erosions were anterior, as if caused by contact with this exposed bone. These observations suggest that degenerative changes are caused by the impingement of the metaphysis against the anterior part of the acetabulum; this would explain the frequent observation that the greater the deformity the greater is the risk of osteoarthritis (Boyer et al 1981; Ordeberg, Hansson and Sandström 1984).

No benefits in any form have been received or will be received from a commercial party related directly or indirectly to the subject of this article.

\section{REFERENCES}

Boyer DW, Mickelson MR, Ponseti IV. Slipped capital femoral epiphysis: long-term follow-up study of one hundred and twentyone patients. J Bone Joint Surg [ Am] 1981; 63-A :85-95.

Busch MT, Morrissy RT. Slipped capital femoral epiphysis. Orthop Clin North Am 1987; 18:637-47.

Hägglund G, Hansson LI, Ordeberg G. Epidemiology of slipped capital femoral epiphysis in southern Sweden. Clin Orthop 1984; 191 : $82-94$.

Hansson LI, Hägglund G, Ordeberg G. Slipped capital epiphysis in Southern Sweden 1910-1982. Acta Orthop Scand 1987; Suppl 226: 9-63.

Kelsey JL, Keggi KJ, Southwick WO. The incidence and distribution of slipped capital femoral epiphysis in Connecticut and southwestern United States. J Bone and Joint Surg [Am] 1970; 52-A:1203-16.
Murray RO. The aetiology of primary osteoarthritis of the hip. $B r J$ Radiol 1965; 38:810-24.

Ordeberg G, Hansson LI, Sandström S. Slipped capital femoral epiphysis in southern Sweden: Long-term result with no treatment or symptomatic primary treatment. Clin Orthop 1984; 191:95-104.

Resnick D. The 'tilt deformity' of the femoral head in osteoarthritis of the hip: a poor indicator of previous epiphysiolysis. Clin Radiol $1976 ; 27: 355-63$.

Stulberg SD, Cordell LD, Harris WH, Ramsey PL, MacEwen GD. Unrecognized childhood hip disease : a major cause of idiopathic osteoarthritis of the hip. In: The hip. Proc 3rd meeting of The Hip Society. St Louis: CV Mosby Co, 1975:212-28.

Weinstein S. Slipped capital femoral epiphysis. AAOS Instructional Course Lectures. St Louis: CV Mosby Co, 1984; 33:310-8. 